\title{
Preparation of Polyimides with Anionic Electrodeposition Coating Ability and the Properties of their Deposition Coatings
}

\author{
Ayumi Kobayashi ${ }^{1 *}$, Hidenobu Wada ${ }^{1}$, Masayuki Yamashita ${ }^{2}$, Seiji Bando ${ }^{2}$, \\ and Takashi Yamashita ${ }^{1^{* *}}$ \\ ${ }^{1}$ Department of Applied Chemistry, School of Engineering, \\ Tokyo University of Technology, 1404-1 Katakura, Hachioji, Tokyo 192-0982, Japan \\ ${ }^{2}$ Functional Chemicals Research Laboratory, Sumitomo Seika Co., Ltd., \\ 346-1 Miyanishi, Harima-cho, Kako-gun, Hyogo 675-0145, Japan \\ *re160038b@edu.teu.ac.jp \\ **yamashitatks@stf.teu.ac.jp
}

\begin{abstract}
With the paradigm shift in the development and utilization of energy systems from petroleum to electricity owing to sustainability considerations, the development of high-performance electrical devices has become increasingly important. Insulating materials are one of the key technologies for the practical application of next-generation electric devices because they must be driven at higher voltages and their complex shapes cannot be coated using current techniques. Therefore, the development of insulating materials with thermostability and facile electrodeposition ability is crucial for the production of high-performance next-generation electric devices. In the current study, anionic electrodeposition coating was successfully performed using poly(amide acid) nanoparticles, which can be converted to polyimides upon thermal annealing. Hybrid coating using polyimide/bentonite with an inorganic filler content of $40 \%$ was also performed, and the resulting electrodeposition films were thermostable to more than $450{ }^{\circ} \mathrm{C}$.
\end{abstract}

Keywords: Electrodeposition, Polyimide, Poly(amide acid), Hybrid coating, Bentonite

\section{Introduction}

Polyimides are one of the most thermostable polymers, being generally thermostable up to $450{ }^{\circ} \mathrm{C}$, as well as exhibiting high tensile strengths, high elastic moduli, and excellent insulating abilities. Accordingly, they have been widely employed as aerospace and electronics materials [1,2]. Recently, they have also been applied as advanced materials, such as liquid crystal alignment films in optoelectronics field [3], dimensionally stable substrates in printable electronics [4], and refractive-index-controllable materials (i.e., photo-optical materials) in photonics [5]. Furthermore, the world is currently facing a paradigm shift in its attitude to energy utilization from petroleum to electricity, and thus the development of novel technologies to help realize a more sustainable society is crucial.
Thus, developing novel technologies for high-performance next-generation electric devices is important. The motors of electric vehicles are currently driven by voltages of up to $700 \mathrm{~V}$. However, the next-generation standard is expected to be $1200 \mathrm{~V}$ because electric power is defined as the product of electric current and electric voltage, and so the electric currents in such motors cannot be increased due to the problems caused by Joule heat [6].

Accordingly, next-generation insulating materials will need to resist electric surges induced by inverter circuits, electrical switching, and electrical noise to prevent their degradation and breakdown [6]. Another advance in electric technologies for the next generation is the invention of electric motors with novel shapes. The coils of conventional electric motors are 
fabricated by winding enamel wires around iron cores. Consequently, they contain fairly large volumes of vacancies between the wires, decreasing motor performance. However, novel coils with rectangular wires allow a more dense packing, drastically increasing performance. The edges of these novel coils, however, cannot be covered using conventional coating techniques, such as dipping, because surface tension causes defects in the coatings, and this retards their practical application.

Electrodeposition coating is a technique in which an electric voltage is applied the substrates as electrodes immersed in a suspension of charged particles, allowing the substrate to be coated without defects [7]. Therefore, developing polyimides with electrodeposition ability would allow the application of defect-free insulation materials with excellent resistance to electric discharges for the next-generation devices.

Polyimides (PI) are usually prepared by the polyaddition of aromatic dianhydrides and aromatic diamines to give poly(amide acid)s (PAAs) followed by imidation via dehydration. The carboxylic acid groups of the PAAs present ionic moieties, allowing charged particles to be prepared for electrodeposition coating (Fig. 1). Iida has reported that ammonium salts of PAAs can be electrically coated onto electrodes [8], but there are few reports on the design and development of electrodeposition materials based on PIs. Consequently, we have investigated the preparation of electrodeposition materials based on PIs and their application to hybrid electrodeposition coatings with inorganic fillers for the improvement of electric properties.

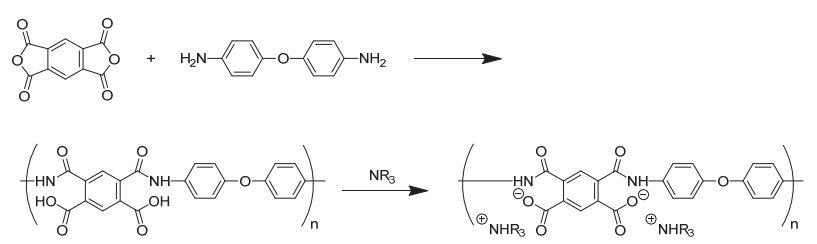

Fig. 1. Scheme of PAA synthesis.

\section{Experimental}

\subsection{Apparatus}

Scanning electron microscope images were recorded on a JSM 6060 with an acceleration voltage of $15 \mathrm{kV}$. Thermal analysis was performed using a thermal gravimetric-differential thermal analyzer (TG-DTA) (Shimadzu Corporation DTG-60) at a heating rate of $10^{\circ} \mathrm{C} / \mathrm{min}$.

\subsection{Reagents}

$\mathrm{N}$-methyl-2-pyrrolidone (NMP) was dried over molecular sieves 4A. Methanol, ethyl acetate, pyridine, triethylamine, phenolphthalein, hexane, toluene, triethanolamine, sodium chloride, and tetrahydrofuran (THF) were obtained from Wako Pure Chemical Industries, Ltd., and used without further purification. $N, N$-dimethyl-n-octylamine, $\mathrm{N}, \mathrm{N}$-dimethylhexadecylamine, ethyl methyl ketone (MEK), tripropylamine, and tributylamine were obtained from Tokyo Chemical Industry Co., Ltd. (TCI) and used without further purification. Organic bentonite was obtained from HOJUN Co., Ltd. and dispersed in THF before use. PAA varnish (Toughclaist) was obtained from Sumitomo Seika. Toughclaist T60 contains 60\% talc whose average particle size is ca. 3-5 $\mu \mathrm{m}$.

\subsection{Preparation of particles}

Polyamic acid nanoparticles were prepared by two methods.

\subsubsection{Method (a)}

PAA varnish diluted with NMP to $1-4 \mathrm{wt} \%$ was precipitated in ethanol as a poor solvent. PAA nanoparticles containing talc were prepared in the same way using PAA varnish containing $60 \%$ talc.

\subsubsection{Method (b)}

THF was added dropwise to PAA varnish diluted with NMP at addition rate of $30 \mathrm{~mL} / \mathrm{min}$ with vigorous stirring, followed by the addition of amines.

\subsection{Electrodeposition procedure}

A PAA nanoparticle suspension was poured into a stainless steel cup equipped with electrodes as the substrates, and electrodeposition was performed under stationary voltage conditions. After deposition, the electrodes were dried at room temperature for $10 \mathrm{~min}$, rinsed with NMP three times, and then baked at 80,110, 190, and $230{ }^{\circ} \mathrm{C}$ for $30 \mathrm{~min}$, respectively.

\subsection{Pinhole test}

A pinhole test solution was prepared by the addition of several droplets of $1 \%$ phenolphthalein solution to $2 \% \mathrm{NaCl}$ aqueous solution. An electric voltage was then applied to an electrolytic bath with the sample as the cathode and a stainless steel plate as the anode. 
Defects in the insulation coating were monitored through their generation of hydroxide ions, which changes the color of the phenolphthalein indicator.

\section{Results and discussion}

3.1. PAA particle preparation by reprecipitation

Nano-sized charged particles are required for stable electrodeposition solutions. We investigated the preparation of PAA nanoparticles by reprecipitation since it is a well-known method for purifying polymers and making fine particles. A $2 \mathrm{wt} \%$ PAA solution (T0) was slowly dropped into methanol. Figure 2 (A) shows a SEM image of the PAA nanoparticles, demonstrating that the particle size is almost uniform and no large aggregates are observed. Two types of particle shapes are observed, i.e., rod-like particles $10 \mu \mathrm{m}$ long and $1 \mu \mathrm{m}$ wide, and round particles of $1 \mu \mathrm{m}$ diameter.

Figure 2 (B) shows the SEM image of the PAA nanoparticles containing talc (T60), revealing that these particles are also dispersed without large aggregates. The average diameter of the particles is $\approx 3 \mu \mathrm{m}$, which is larger than that of T0. In addition, square particles are observed as well as rod-like or round particles. These observations indicate that some of the talc is wrapped in PAA nanoparticles, and some is dispersed in the solution.

3.2. Electrodeposition of PAA particles prepared by reprecipitation

Negatively charged PAA particles were obtained by neutralization of the carboxylic acid group of the PAA with the addition of amines to give carboxylate anions. The chemical structures of the amines and the electrodeposition conditions are summarized in Table 1. The

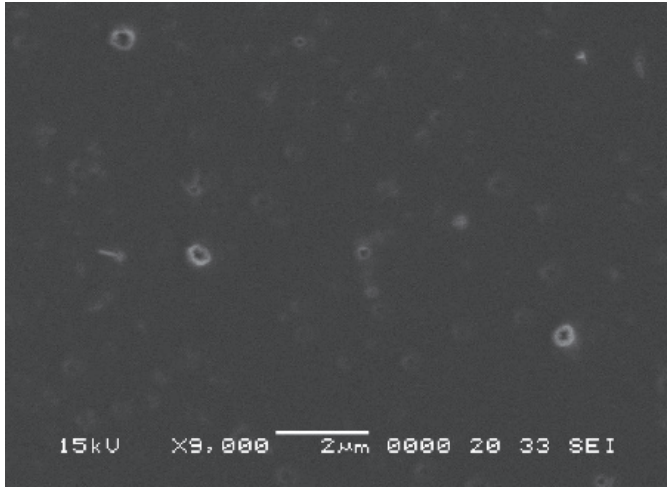

(A)

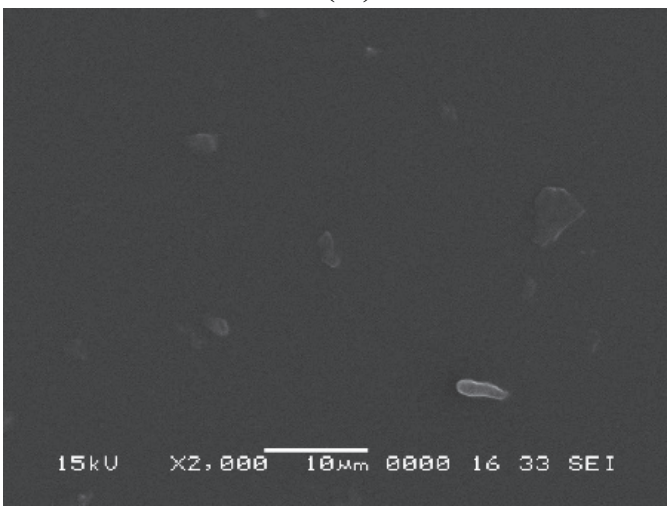

(B)

Fig. 2. (A) SEM image of the PAA nanoparticles (T0). (B) SEM image of the PAA nanoparticles containing talc (T60).

mechanism of the electrodeposition is thought to involve the destabilization of the charged particles resulting from a change in $\mathrm{pH}$ around the electrodes, but the actual mechanism is more complex. A quantitative discussion on the electrodeposition mechanism will be presented elsewhere.

At the beginning of our study, the electrodeposition of PAA particles without the addition of an amine was performed using a stainless steel electrode as a cathode to provide a brittle coating layer (run 1). Then, addition of

Table 1. Effect of the pyridine equivalent added to the PAA particles.

\begin{tabular}{|c|c|c|c|c|c|c|c|c|c|}
\hline \multirow{2}{*}{ run } & \multirow{2}{*}{$\begin{array}{c}\text { PAA } \\
(\mathrm{g})\end{array}$} & \multicolumn{3}{|c|}{ solvent $(\mathrm{mL})$} & \multicolumn{2}{|c|}{ amine } & \multirow{2}{*}{$\begin{array}{c}\text { voltage } \\
\text { (V) }\end{array}$} & \multirow{2}{*}{ cathode } & \multirow{2}{*}{ property of film } \\
\hline & & NMP & methanol & THF & & eq. & & & \\
\hline 1 & 0.015 & 1.4 & 50.3 & - & - & - & 50 & stainless & brittle \\
\hline 2 & 0.015 & 1.5 & 50.3 & - & TEA & 1 & 50 & stainless & thin \\
\hline 3 & 0.015 & 1.5 & 50.3 & - & TEA & 1 & 250 & stainless & brittle \\
\hline 4 & 0.015 & 1.5 & 50.2 & - & Py & 1 & 250 & stainless & homogeneous \\
\hline 5 & 0.015 & 1.5 & 50.2 & - & Py & 1 & 250 & copper & greenish and brittle \\
\hline 6 & 0.071 & 7.0 & - & 9.3 & Py & 1 & 250 & copper & wrinkle pattern \\
\hline 7 & 0.070 & 6.9 & - & 9.2 & Py & 0.8 & 250 & copper & wrinkle pattern \\
\hline 8 & 0.072 & 7.1 & - & 9.4 & Py & 0.6 & 250 & copper & wrinkle pattern \\
\hline 9 & 0.071 & 7.0 & - & 9.4 & Py & 0.4 & 250 & copper & homogeneous \\
\hline 10 & 0.069 & 7.1 & - & 9.5 & Py & 0.2 & 250 & copper & homogeneous \\
\hline
\end{tabular}


Table 2. Effect of non-aqueous solvent added to the PAA particles on the electrodeposition films.

\begin{tabular}{ccccccc}
\hline \multirow{2}{*}{ run } & PAA & NMP & \multicolumn{2}{c}{ solvent } & amine & property of film \\
& $(\mathrm{g})$ & $(\mathrm{ml})$ & & $(\mathrm{g})$ & & greenish \\
& 0.013 & 1.3 & ethanol & 31.4 & Py & greenish \\
2 & 0.013 & 1.3 & acetonitrile & 27.3 & Py & wrinkle pattern \\
3 & 0.16 & 16.3 & ethyl acetate & 152.5 & Py & blackish and brittle \\
\hline
\end{tabular}

triethanolamine (TEA) to the PAA particles improved the properties of the coating films (run 2). Increasing the voltage of the deposition to 250 $\mathrm{V}$ resulted in thin brittle layers (run 3). Addition of pyridine (Py) instead of TEA gave excellent deposition films, and these conditions were chosen as optimal for electrodeposition (run 4).

Next, electrodeposition was performed in the same conditions using a copper plate as the cathode, but a brittle greenish film was obtained (run 5). This is thought to occur because some of the pyridine coordinates to the copper to dissolve it, because the effective amount of the carboxylic groups on the surface of the PAA particles is smaller than the total amount of the carboxylic acids, and because all of the added pyridine is not neutralized by the carboxylic groups of the PAA. Therefore, the effect of changing the amount of pyridine was investigated by changing it from 1 to 0.2 . Runs $6-10$ in Table 1 show the effect of the amount of pyridine added to the PAA particles on the quality of the electrodeposited film. A decrease in the pyridine amount increases the homogeneity of the deposition films, and a wrinkled pattern is observed on the films when between 0.6 and 1 equivalents of pyridine are used. However, the use of between 0.4 and 0.2 equivalents results in a relatively good quality of deposition film.

3.3. PAA particle preparation by poor-solvent addition

Anionic electrodeposition coating was successfully performed using PAA nanoparticles obtained by the reprecipitation method, but the concentration of the particle solution is not high enough for practical applications. Therefore, the preparation of a high-concentration suspension was investigated. Water was added dropwise to a 10 or $2 \mathrm{wt} \%$ PAA solution in NMP to give fine PAA particles, but the conditions were so severe that aggregation of PAA sometimes occurred. The addition of 1 equivalent of pyridine to the PAA particles provided negatively charged particles, and so the electrodeposition was performed using a copper electrode as the cathode. However, a greenish electrodeposition coating was obtained due to corrosion of the copper electrode.

\subsection{PAA particle preparation by addition of non-aqueous solvent}

Another problem is that the PAA particles suspended in aqueous media are not very stable, since the PAA main chain is susceptible to hydrolysis, decreasing the molecular weight, meaning that the coated film becomes brittle. Therefore, preparation of PAA particles by the addition of a non-aqueous poor solvent was investigated. The addition of THF as a poor solvent to a PAA solution prepared in NMP gave very fine particles with good reproducibility, and the stability of the suspension was quite high. The particle size was as small as $20-100 \mathrm{~nm}$, and the zeta potential was $-4 \mathrm{mV}$. Other poor solvents, such as acetone, ethyl acetate, acetonitrile, or MEK also gave suspensions, but they were relatively unstable. The results of the electrodepositions are summarized in Table 2.

3.5. Effect of amine structure on the electrodeposition of films prepared by the addition of non-aqueous solvent

We have already investigated the solubility of various ammonium salts of PAAs, revealing that amines with alkyl chains shorter than octyl groups make the PAA salts soluble in water, but amines with longer alkyl chains make PAA salts insoluble in water due to the increase in hydrophobicity [9]. Therefore, the effect of amines on the electrodeposition as the counter cations was investigated. Addition of triethylamine, tripropylamine, and tributylamine did not cause precipitation of particles, but addition of $\mathrm{N}, \mathrm{N}$-dimethyl-n-octylamine or $\mathrm{N}, \mathrm{N}$-dimethylhexadecylamine caused precipitation of the PAA particles. This result is explained by the fact that 
counter ions with longer alkyl groups make electrically shielded particles whose zeta potentials approach the isoelectric point to induce aggregation. Therefore, addition of alkylamines with shorter chain lengths is favorable for the preparation of stable electrodeposition solutions.

3.6. Electrodeposition of PAA particles prepared by the addition of non-aqueous solvent

Figure 3 shows images of electrodeposition coated films prepared using THF or MEK as the poor solvent and pyridine as the base. The film prepared by the addition of THF appears pale brown before annealing and turns dark brown after thermal annealing at $230{ }^{\circ} \mathrm{C}$ for $60 \mathrm{~min}$. The edge of the plate was found to be completely coated without defect by the pinhole test. The film prepared by the addition of MEK appears similar to that with THF, but turns blackish brown after annealing, and partial peeling of the film at the edge of the plate is observed. Thus, electrodeposition coating using THF as a poor solvent was found to give high quality films.

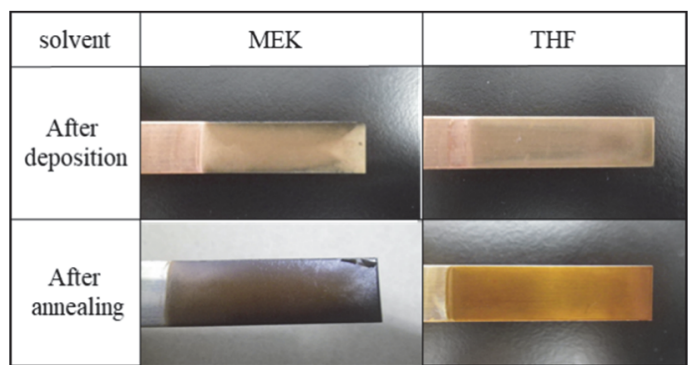

Fig. 3. Electrodeposition films coated using THF or MEK.

\subsection{Hybrid electrodeposition of mixed particles} of PAA and clays

Electrodeposition of PAA particles containing inorganic fillers was investigated with the intention of producing coated layers with higher thermostabilities and electric discharge resistances.

Initially, talc was mixed with PAA particles prepared by the reprecipitation method, which gave hybrid electrodeposition coated films containing $30 \%$ talc, as revealed by thermal analysis measurements. However, talc is not dispersed in common organic solvents such as THF, and so talc cannot be applied for hybrid electrodeposition using non-aqueous solvent systems. Therefore, we investigated the preparation of hybrid solutions using bentonite clays with alkylamines as counter ions. The dispersion abilities of the clays in THF were
Table 3. Chemical structure and the dispersion ability.

\begin{tabular}{|c|c|c|c|}
\hline \multirow{2}{*}{$\begin{array}{l}\text { organic clays ; } \\
\text { S-BENs }\end{array}$} & \multicolumn{2}{|c|}{ surface-modifying agent } & \multirow{2}{*}{$\begin{array}{l}\text { dispersion ability } \\
\text { in THF }\end{array}$} \\
\hline & structure & amount (\%) & \\
\hline $\bar{E}$ & TMS & 25.6 & $x$ \\
\hline NZ70 & BDMS & 51.4 & 0 \\
\hline $\mathrm{W}$ & DMDS & 37.2 & $x$ \\
\hline N400 & DMDS & 39.3 & 0 \\
\hline $\mathrm{NX}$ & DMDS & 41.8 & 0 \\
\hline NX80 & DMDS & 49.9 & O \\
\hline NO12S & OHEM & 31.5 & $x$ \\
\hline NEZ & TMS+BDMS & 37.5 & 0 \\
\hline NO12 & DMDS+OHEM & 38.8 & $x$ \\
\hline wX & $\mathrm{DMDS}+\mathrm{BDMS}$ & 39.0 & $x$ \\
\hline $\mathrm{NE}$ & DMDS+TMS & 45.3 & 0 \\
\hline \multicolumn{4}{|c|}{$\begin{array}{l}\text { DMDS : Dimethyldialkylammonium } \\
\text { OHEM : Alkylbis (2-hydroxyethyl) methylammonium } \\
\text { TMS : Trimethylalkylammonium } \\
\text { BDMS : Benzyldimethylalkylammonium }\end{array}$} \\
\hline $0:$ good dispe & $\times:$ pre & tation & \\
\hline
\end{tabular}

investigated by observing $5 \%$ mixtures of the clay $(0.5 \mathrm{~g})$ and THF $(9.5 \mathrm{~g})$. The chemical structures and dispersion abilities are summarized in Table 3. The S-BENs NO12, NO12S, WX, E, and $\mathrm{W}$ produced precipitations, while $\mathrm{NX}, \mathrm{NZ70}$, NX80, NE, NEZ, and N400 provided welldispersed suspensions. Thus, S-BEN NE and S-BEN NEZ were used for hybrid electrodeposition.

An electrodeposition solution was prepared by adding the S-BEN to the PAA particles prepared by the addition of THF to PAA. The compositions of the solutions are summarized in Table 4. Electrodeposition was performed using copper electrodes as the cathode at $200 \mathrm{~V}$ for $10 \mathrm{~min}$.

Table 4. Composition of electrodeposition solutions.

\begin{tabular}{ccccccc}
\hline \multirow{2}{*}{ run } & PAA & NMP & THF & amine & \multicolumn{2}{c}{ organic clays (1wt\% in THF) } \\
\cline { 6 - 7 } & $(\mathrm{g})$ & $(\mathrm{g})$ & $(\mathrm{g})$ & & S-BENs & $(\mathrm{g})$ \\
\hline 1 & 0.36 & 17.6 & 60 & TEA & $\mathrm{NE}$ & 6.0 \\
2 & 0.36 & 17.6 & 60 & TPA & NE & 6.0 \\
3 & 0.36 & 17.6 & 60 & TPA & NEZ & 6.0 \\
4 & 0.36 & 17.6 & 60 & TBA & NE & 6.0 \\
5 & 0.36 & 17.6 & 60 & DMOA & NE & 6.0 \\
6 & 0.36 & 17.6 & 60 & DMHDA & NE & 6.0 \\
\hline
\end{tabular}

TEA : trimethylamine / TPA : tripropylamine / TBA : tributhylamine / DMOA N,N-dimethyl-n-octylamine / DMHDA : N,N-dimethylhexadecylamine

The surface appearance of the electrodeposition film without S-BEN was glossy, like a conventional polyimide film, and the film became increasingly matt with increasing clay content. Figure 4 (A) shows an image of the electrode coated by a mixture of PAA, S-BEN, and tributylamine after imidation by heating to $230{ }^{\circ} \mathrm{C}$. Blowholes are observed all over the film surface because hybridization of clay in PI increases the gas barrier ability of the film to 
disturb the evaporation of the remaining solvent or elimination of water [10].

To improve the adhesion of the coated layer, chemical imidation instead of thermal annealing was investigated, because the toughness of a PI film allows it to endure the evaporation of low-weight molecules, and so converting PAA to $\mathrm{PI}$ in the lower temperature region is preferable. An electrodeposition coated electrode was immersed in a chemical imidation solution composed of acetic anhydride and pyridine (1:1) at $50{ }^{\circ} \mathrm{C}$ for $1 \mathrm{~h}$, but the coating layer peeled off. Dilution of the imidation solution in m-xylene was also ineffective. Finally, we found that rinsing the electrodeposition coated film in NMP to substitute the THF followed by thermal imidation is effective for obtaining hybrid films of good quality without peeling.

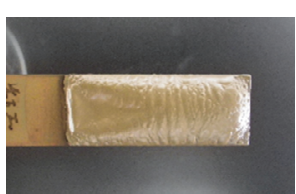

(A)

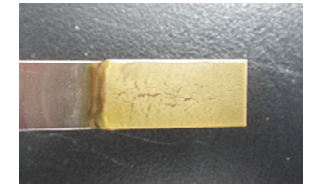

(B)
Fig. 4. Photo of the electrode electrodeposition coated by a mixture of (A) PAA, S-BEN NE, and tributylamine without rising in NMP, and (B) PAA, S-BEN NE, and tripropylamine with rising in NMP.

Figure 4 (B) shows an image of and copper electrode electrodeposition coated using PAA, S-BEN NE, and tripropylamine. The appearance of the film is pale yellow due to the inclusion of clays, which turned to a homogeneous film without defects upon thermal imidation, as confirmed by the pinhole test.

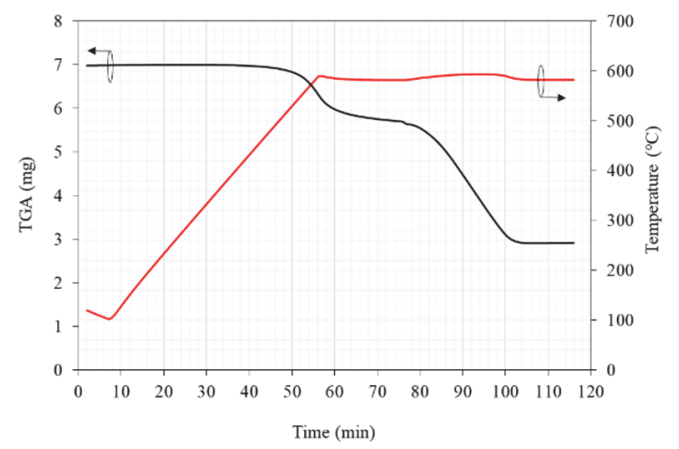

Fig. 5. Thermal analysis of the electrodeposition layer after imidation.

Figure 5 shows the thermal analysis results for of the electrodeposition coated layer after imidation. The weight decreases gradually above $250{ }^{\circ} \mathrm{C}$, and the $10 \%$-weight-loss temperature was found to be as high as $450{ }^{\circ} \mathrm{C}$. The clay content of the film was calculated to be $40 \%$ by heating the film at $600{ }^{\circ} \mathrm{C}$ for $1 \mathrm{~h}$ to burn off the organic polymer.

\section{Conclusion}

PAA nanoparticles with diameters of $20-100$ $\mathrm{nm}$ were prepared by reprecipitation or poor-solvent addition. Electrodeposition coating materials were prepared by the addition of amines to the PAA nanoparticles, and amines with shorter alkyl chains gave more stable charged particles. Electrodeposition was performed under stationary voltage conditions. Preparing PAA nanoparticles by the addition of an organic solvent such as THF is preferable as it prevents hydrolysis of PAA. Hybrid electrodeposition was also performed with a solution containing bentonite clay as an inorganic filler, producing a film with a thermostability as high as $450{ }^{\circ} \mathrm{C}$. This technique is expected to be a key technology for realizing next-generation electric devices.

\section{Acknowledgment}

The authors would like to express sincere gratitude to Dr. Takeo Ebina, Dr. Takashi Nakamura for providing organic clays and valuable discussions.

\section{References}

1. C. E. Sroog, J. Polym. Sci., Macromol. Rev., 11 (1976) 161.

2. K. Horie and T. Yamashita, Eds., Photosensitive Polyimides: Fundamental and Applications, Technomic (1996).

3. B. Myrvold, Liq. Cryst., 7 (1990) 261.

4. W. Shao, G. Li, P. Zhu, Y. Zhang, Q. Ouyang, R. Sun, C. Chen, and C.-P. Wong, J. Mater. Sci. Mater. Elec., 29 (2018) 4432.

5. H. Onozeki, J. Kato, Y. Maekawa, Y. Muroya, Y. Katsumura, and T. Yamashita, Proc. RadTech Asia 03, (2003) 618.

6. N. Hayashizaka, K. Kawasaki, M. Yamashita, T. Ebina, T. Ishida, and S. Hattori, PCT Int. Appl. WO 2017006999 A1 20170112 (2017).

7. Y. Kim, H. Kim, and J. Hong, J. Appl. Polym. Sci., 102 (2006) 5566.

8. S. Nakamura, K. Iida, and G. Sawa, Proc. SPIE, 72 (1996) 2780.

9. T. Yamashita and T. Miura, J. Photopolym. Sci. Technol., 20 (2007) 743.

10. N. Onozawa-Komatsuzaki, K. Sayama, Y. Konishi, H. Sugihara, K. Kawasaki, and T. Ebina, Electrochemistry, 79 (2011) 801. 